\title{
Efeito da remoção de células somáticas pela microfiltração sobre a lipólise do leite
}

Marcos Veiga dos SANTOS ${ }^{1}$ Carlos Augusto Fernandes OLIVEIRA ${ }^{2}$

Ygor Vinícius Real de LIMA $^{1}$

Bruno Garcia BOTARO ${ }^{1}$

Correspondência para:

Departamento de Nutrição e Produção Animal-VNP

Cx Postal 23, R. Duque de Caxias Norte, 225, Pirassununga, SP, 13635.900, Brasil. Fone: 55193565 4240, FAX: 5519561 6215, e-mail:mveiga@usp.br

Recebido para publicação: 07/12/2005 Aprovado para publicação: 07/06/2007

1 - Departamento de Nutrição e Produção Animal, Faculdade de Medicina Veterinária

e Zootecnia, Universidade de São Paulo. Pirassununga - SP

2 - Faculdade de Zootecnia e Engenharia de Alimentos, Universidade de São Paulo, Pirassununga - SP

\section{Resumo}

O objetivo do presente estudo foi avaliar o efeito da retirada mecânica das células somáticas do leite cru sobre a taxa de lipólise durante o armazenamento refrigerado do leite pasteurizado. O delineamento experimental utilizado foi totalmente casualizado, com três repetições e arranjo fatorial de tratamentos 2 X 2 X 2, constituídos por dois nível de gordura do leite (desnatado e integral), dois níveis de contagem de células somáticas (CCS baixa - CCSB e CCS alta - CCSA), e pela aplicação ou não da microfiltração ao leite. Três lotes de leite cru CCSB (75.000 cél./mL) e CCSA (1.150.000 cél./mL) foram obtidos de vacas selecionadas e submetidos ao desnate centrífugo, à microfiltração em sistema a vácuo, sendo em seguida pasteurizados e armazenados por 21 dias sob refrigeração a $6^{\circ} \mathrm{C}$. Foram realizadas medidas repetidas no tempo, as quais corresponderam aos dias de coleta do leite pasteurizado durante o período de armazenamento (1, 7, 14 e 21). A microfiltração associada ao desnate foram eficazes na remoção das células somáticas do leite, com reduções de 92,5 e 99,5\% para o leite CCSB e CCSA, respectivamente. A lipólise do leite aumentou em função do tempo de armazenamento e foi maior para o leite microfiltrado, contudo não sofreu influência da CCS. Independentemente da CCS, ocorreu aumento da lipólise do leite pasteurizado durante o período de armazenamento.

\section{Introdução}

A elevação da contagem de células somáticas (CCS) no leite está associada à alteração da composição e vida de prateleira do leite e dos derivados lácteos, resultando em prejuízos para produtores e indústria de laticínios. A elevada CCS do leite causa diminuição da vida de prateleira do leite pasteurizado e afeta negativamente a sua qualidade sensorial ${ }^{1,2}$, em razão da ação de lipases sobre os triacilglicerídios, o que resulta no aparecimento de alterações sensoriais, como a rancidez. Com base nestes estudos, o leite com alta CCS apresenta atividade lipolítica aumentada, mesmo após a pasteurização. No entanto, não foi determinada a causa desta atividade lipolítica durante a mastite, a qual poderia ter origem a partir das próprias células somáticas, do sangue e da lipase lipoprotéica do leite.

Os neutrófilos e macrófagos compõem a maioria das células somáticas do leite de vacas com mastite e apresentam grande variedade de enzimas proteolíticas e lipolíticas, as quais são liberadas durante o mecanismo de morte intracelular de microrganismos, e contribuem o aumento da proteólise e lipólise dos constituintes do leite. ${ }^{1}$ As concentrações de muitas enzimas ou mesmo a sua atividade enzimática no leite encontram-se aumentadas durante a mastite. ${ }^{3}$

A lipólise é a hidrólise enzimática da gordura do leite e apresenta efeito negativo sobre o seu sabor, sendo também conhecida como rancidez. ${ }^{4}$ Quando submetido à 
agitação ou turbulência em excesso, a membrana dos glóbulos de gordura do leite (MGGL) pode ser rompida, permitindo que enzimas lipolíticas, em especial a lipase lipoprotéica (LLP), tenham acesso ao seu substrato, os triacilglicerídeos, que podem ser hidrolisados sob ação enzimática.

A microfiltração (MF) é um processo de separação por membranas que permite a concentração diferencial dos componentes que são maiores que o diâmetro do poro da membrana. ${ }^{5}$ As principais aplicações da MF na indústria de laticínios são: remoção de bactérias e células somáticas, remoção de gordura do soro e enriquecimento micelar do leite para fabricação de queijos. ${ }^{6}$ No entanto, a remoção física das células somáticas do leite pela MF não implica necessariamente na reversão dos efeitos negativos que alta CCS acarreta na composição e qualidade do leite, uma vez que muitas das alterações ocorrem ainda no leite dentro do úbere, antes da ordenha. ${ }^{7}$ Desta forma, o objetivo do presente estudo foi avaliar os efeitos da retirada mecânica das células somáticas do leite, pelo uso da microfiltração, sobre a taxa de lipólise durante o armazenamento refrigerado do leite pasteurizado.

\section{Material e Método}

\section{Delineamento experimental}

O delineamento experimental utilizado foi totalmente casualizado e contou com três repetições. Utilizou-se um arranjo fatorial de tratamentos do tipo $2 \times 2 \times 2$, constituído por: dois nível de gordura do leite (desnatado e integral), dois níveis de contagem de células somáticas (CCS baixa CCSB e CCS alta - CCSA), e pela aplicação ou não da microfiltração ao leite, adicionado do fator medidas repetidas no tempo, as quais corresponderam às avaliações do leite pasteurizado durante o período de armazenamento (um, sete, 14 e 21 dias).

\section{Seleção de vacas e coleta de leite}

Para a seleção das vacas utilizou-se do rebanho leiteiro da Universidade de São
Paulo, campus de Pirassununga-SP, composto de vacas da raça Holandesa ordenhadas em regime de duas ordenhas diárias. Foram coletadas amostras individuais de leite de todas as vacas entre 30 e 250 dias em lactação as quais foram submetidas para análise de CCS e composição (gordura, proteína bruta, lactose, sólidos totais). A análise de CCS foi realizada por citometria fluxométrica utilizando-se o equipamento Bentley Somacount 300 (Bentley Instruments Inc. Chasca, MN, USA) e as análises de composição foram baseadas em metodologia por absorção infravermelha no equipamento Bentley 2000 (Bentley Instruments Inc. Chaska, MN, USA).

Foram selecionadas, em média, quatro vacas cujo leite apresentava baixa CCS (aproximadamente 100.000 cél./mL) e quatro vacas cujo leite apresentava alta CCS (aproximadamente 1.000.000 cél./mL), de forma a manter similares os níveis de gordura e proteína entre si. No dia de cada coleta, as vacas selecionadas foram ordenhadas individualmente na ordenha da manhã, sendo todo o leite coletado separadamente e a sua produção medida. O leite cru de cada vaca selecionada foi armazenado em latões de polipropileno previamente higienizados e imediatamente resfriados a $4^{\circ} \mathrm{C}$.

\section{Processamento e remoção das células somáticas do leite}

Após o resfriamento, 10 litros de leite cru de alta (CCCA) e baixa (CCSB) CCS foram aquecidos a $50^{\circ} \mathrm{C}$ e submetidos ao desnate centrífugo utilizando-se uma desnatadeira. Após o desnate, foram formados os seguintes lotes: leite cru integral com baixa CCS (tratamento A), leite desnatado de baixa CCS (tratamento B), creme do leite de baixa CCS, leite integral com alta CCS (tratamento E), leite desnatado de alta CCS (tratamento F) e creme do leite de alta CCS.

Os lotes de leite cru desnatados (tratamentos $\mathrm{B}$ e F) foram submetidos à microfiltração em sistema a vácuo. A 
metodologia para remoção das células somáticas do leite baseou-se nos procedimentos descritos por Verdi e Barbano $^{8}$, nos quais a amostra de leite é filtrada em membrana éster de celulose com diâmetro de poro de $5,0 \mathrm{~mm}$ (Millipore, Brasil), em sistema a vácuo. O sistema era composto por uma bomba laboratorial de vácuo e um suporte de vidro para filtração com diâmetro de $47 \mathrm{~mm}$ (Phenomenex, USA). Para maior eficiência da microfiltração, o leite foi previamente aquecido em banho-maria a $50{ }^{\circ} \mathrm{C}$.

Após a microfiltração, foram obtidos os seguintes lotes de leite cru: desnatado microfiltrado com baixa CCS (tratamento C) e desnatado microfiltrado com alta CCS (tratamento G). Os leites integrais, desnatados e os cremes de alta e baixa CCS foram submetidos à análise de gordura do leite pelo método de Gerber ${ }^{9}$, para a padronização dos lotes de leite integral microfiltrado com baixa (tratamento D) e alta CCS (tratamento $\mathrm{H}$ ).

Os lotes de leite de todos os tratamentos foram transferidos para erlenmeyers de vidro de $500 \mathrm{~mL}$ previamente higienizados e submetidos à pasteurização lenta $\left(65^{\circ} \mathrm{C}, 30\right.$ minutos) em banho-maria. Imediatamente após a pasteurização, foram coletadas amostras de leite de todos os tratamentos para confirmar a eficácia da pasteurização pelas provas enzimáticas da fosfatase e peroxidase ${ }^{9}$, após o término da pasteurização e resfriamento do leite, foi adicionado em todos os tratamentos o conservante dicromato de potássio, na concentração final no leite de $0,1 \mathrm{mg} / \mathrm{kg}$. Tal procedimento foi realizado para evitar a multiplicação microbiana no leite durante 21 dias de armazenamento, e desta forma a evitar a lipólise e proteólise de origem microbiana. Os lotes de leite de todos os tratamentos foram resfriados à temperatura de $6^{\circ} \mathrm{C}$, embalados individualmente em frascos plásticos (capacidade $50 \mathrm{~mL}$ ) e armazenados por 21 dias sob refrigeração $\left(6^{\circ} \mathrm{C}\right)$ em estufa (modelo TE 390, marca Tecnal, Brasil).

\section{Análise do leite antes e após o processamento}

Antes do processamento, foram coletadas amostras de leite cru de todos os tratamentos para realização das análises de composição (proteína bruta, gordura, lactose, sólidos totais) e a CCS. Após o processamento (microfiltração e pasteurização), foram coletadas amostras de leite dos diferentes tratamentos no primeiro dia (imediatamente após a pasteurização), bem como no $7^{\circ}, 14^{\circ}$ e $21^{\circ}$ dias com vistas à determinação da concentração de ácidos graxos livres (AGL) no leite. A mudança na concentração de AGL no leite foi utilizada para mensuração da lipólise do leite. A concentração de AGL do leite foi determinada utilizando-se o método de sabão de cobre ${ }^{10} \mathrm{com}$ algumas modificações ${ }^{11}$, sendo os resultados expressos em meq de AGL/kg de leite.

Imediatamente após a pasteurização e no $21^{\circ}$ dia de armazenamento, foram coletadas amostras de leite de todos os tratamentos para realização de análises microbiológicas (contagem bacteriana total, contagem de coliformes totais e fecais), de acordo com metodologia descrita por Marshal $^{12}$.

\section{Análise estatística}

Os resultados obtidos foram submetidos à estatística descritiva (médias aritméticas e desvio padrão), análise de variância, aos quais foram separados como causas principais de variação dois níveis de CCS (alta e baixa), níveis de gordura (desnatado ou integral), aplicação ou não da microfiltração e as interações entre estes fatores. Posteriormente, foi adicionado o fator de medidas repetidas (comando Repeated do Procedimento General Linear Model do SASầ, Versão 8.02; SAS Institute Inc., Cary NC), referentes aos quatro diferentes tempos de armazenamento $(1,7,14$ e 21$)$.

\section{Resultados e Discussão}

Composição do leite cru antes e 
após o processamento

As médias da composição do leite cru antes do processamento dos diferentes tratamentos (contagem de células somáticas, porcentagem de gordura, proteína bruta, lactose e teor de sólidos totais) estão apresentadas na tabela 1. Após a aplicação da MF, os resultados de CCS do leite cru dos diferentes tratamentos confirmaram a eficiência do procedimento quanto à remoção das células somáticas do leite $(\mathrm{P}<0,05)$. O desnate do leite teve efeito com o leite que não passou pela MF $(0,151$ $\mathrm{meq} / \mathrm{kg}$ ).

A lipólise, que pode ser definida como a hidrólise enzimática da gordura do leite, apresenta como uma das principais características, o seu efeito negativo sobre o sabor do leite, também conhecida como rancidez ou rancidez hidrolítica. ${ }^{4}$ A lipólise pode ocorrer devido a diversas causas, sendo que fatores fisiológicos e mecânicos apresentam grandes impactos sobre a lipólise. Por exemplo, se o leite cru for submetido à

Tabela 1 - Composição química média $(n=3)$ e contagem de células somáticas (CCS) do leite cru, distribuído pelo nível de gordura, CCS e aplicação de microfiltração. Pirassununga, 2006

\begin{tabular}{|c|c|c|c|c|c|c|c|c|c|c|}
\hline \multirow{3}{*}{$\begin{array}{l}\text { Nivel de gordura } \\
\text { CCS } \\
\text { Microfiltração }\end{array}$} & \multicolumn{4}{|c|}{ Desnatado } & \multicolumn{4}{|c|}{ Integral } & \multirow{3}{*}{$\begin{array}{c}\text { Média } \\
\text { geral }\end{array}$} & \multirow{3}{*}{$\begin{array}{l}\text { Desvio } \\
\text { Padrão }\end{array}$} \\
\hline & \multicolumn{2}{|c|}{ Alta } & \multicolumn{2}{|c|}{ Baixa } & \multicolumn{2}{|c|}{ Alta } & \multicolumn{2}{|c|}{ Baixa } & & \\
\hline & Sim & Não & Sim & Não & Sim & Não & Sim & Não & & \\
\hline CCS (x 1000 cél./ml) & 5 & 279,5 & 5,5 & 49 & 2,5 & 1150 & 115 & 75 & 251,2 & 491,5 \\
\hline Gordura (\%) & 0,47 & 0,54 & 0,51 & 0,47 & 4,58 & 3,00 & 3,20 & 3,58 & 2,0 & 1,7 \\
\hline Proteína bruta (\%) & 3,12 & 3,01 & 3,11 & 3,08 & 2,79 & 2,99 & 3,00 & 2,87 & 3,0 & 0,2 \\
\hline Lactose (\%) & 4,07 & 4,01 & 4,59 & 4,53 & 3,80 & 3,87 & 4,42 & 4,34 & 4,2 & 0,3 \\
\hline Sólidos totais (\%) & 8,36 & 8,25 & 9,22 & 9,06 & 11,91 & 10,57 & 11,65 & 11,79 & 10,1 & 1,5 \\
\hline Ácidos graxos livres (meq $/ \mathrm{kg}$ ) & 0,08 & 0,07 & 0,06 & 0,07 & 0,16 & 0,13 & 0,12 & 0,15 & 0,1 & 0,1 \\
\hline
\end{tabular}

significativo sobre a CCS $(\mathrm{P}<0,05)$, sendo que para os tratamentos de baixa (tratamento A) e alta (tratamento E) CCS houve redução em 34,6\% (75.000 versus 49.000 cél. $/ \mathrm{ml})$ e $75,6 \%(1.150 .000$ versus 279.500 cél. $/ \mathrm{ml}) \mathrm{da}$ CCS, respectivamente, confirmando resultados obtidos por Santos, Ma e Barbano ${ }^{1}$. Adicionalmente, o desnate seguido da MF resultou em redução da CCS dos tratamentos de baixa (tratamento A) e alta (tratamento E) CCS em 92,6\% (75.000 versus 5.500 cél. $/ \mathrm{ml})$ e 99,5\% (1.150.000 versus 5.000 cél. $/ \mathrm{ml}$ ), respectivamente, o que concorda com resultados apresentados por Giffel e Horst ${ }^{13}$.

Efeito do nível de CCS e da microfiltração sobre a lipólise do leite pasteurizado

As médias da concentração de AGL no leite pasteurizado armazenado pelo período de 21 dias estão apresentadas na tabela 2. Foi observado efeito significativo do tempo de armazenamento $(\mathrm{P}=0,001)$ e da $\mathrm{MF}(\mathrm{P}=0,002)$ sobre a concentração de AGL no leite. A média geral da concentração de AGL no leite foi maior para o leite que sofreu MF $(0,192 \mathrm{meq} / \mathrm{kg})$ em comparação agitação ou turbulência em excesso, a membrana dos glóbulos de gordura do leite (MGGL) pode ser rompida, permitindo que enzimas lipolíticas, em especial a lipase lipoprotéica (LLP), tenham acesso ao seu substrato, os triacilglicerídeos, que podem ser hidrolisados sob ação enzimática. Outras possíveis causas de lipólise espontânea no leite são: elevadas concentrações de constituintes do sangue no leite, final da lactação, nutrição inadequada e mastite. ${ }^{14,15}$

Os resultados do presente estudo são conflitantes com os resultados obtidos por Santos, Ma e Barbano ${ }^{1}$ os quais relataram que a CCS apresentou correlação positiva com a concentração de AGL no leite. Segundo Downey ${ }^{14}$, a mastite aumenta a susceptibilidade do leite à ação hidrolítica das lipases. Jurczak e Sciubisz ${ }^{16}$ identificaram uma relação linear entre a CCS no leite e a sua lipólise até a CCS de 1.400 .000 cél./mL, sendo que em CCS superiores houve redução da taxa de lipólise. De forma contrária, Cartier e Chilliard ${ }^{15}$ descreveram que a lipólise do leite não estava correlacionada com a CCS. 
Tabela 2 - Efeito do nível de gordura, CCS, microfiltração e tempo de armazenamento do leite pasteurizado sobre a lipólise do leite (ácidos graxos livres, meq/kg). Pirassununga, 2006

\begin{tabular}{|c|c|c|c|c|c|c|c|}
\hline & Tratame & & & Armaz & ento $(\mathrm{d}$ & & \\
\hline Nível de Gordura & $\mathrm{CCS}$ & Microfilttração & 1 & 7 & 14 & 21 & Média \\
\hline \multirow{4}{*}{ Desnatado } & \multirow{2}{*}{ Alta } & Sim & 0,080 & 0,091 & 0,077 & 0,129 & 0,094 \\
\hline & & Não & 0,097 & 0,098 & 0,115 & 0,127 & 0,109 \\
\hline & \multirow{2}{*}{ Baixa } & Sim & 0,096 & 0,107 & 0,109 & 0,115 & 0,107 \\
\hline & & Não & 0,124 & 0,110 & 0,133 & 0,126 & 0,123 \\
\hline \multirow{4}{*}{ Integral } & \multirow{2}{*}{ Alta } & Sim & 0,235 & 0,369 & 0,251 & 0,264 & 0,280 \\
\hline & & Não & 0,126 & 0,309 & 0,147 & 0,176 & 0,190 \\
\hline & \multirow{2}{*}{ Baixa } & Sim & 0,255 & 0,233 & 0,308 & 0,350 & 0,287 \\
\hline & & Não & 0,157 & 0,221 & 0,145 & 0,198 & 0,180 \\
\hline \multicolumn{8}{|c|}{ Efeitos Principais } \\
\hline Desnatado & & & 0,099 & 0,101 & 0,109 & 0,124 & 0,108 \\
\hline \multirow[t]{5}{*}{ Integral } & & & 0,193 & 0,283 & 0,213 & 0,247 & 0,234 \\
\hline & Alta & & 0,158 & 0,168 & 0,174 & 0,197 & 0,174 \\
\hline & Baixa & & 0,135 & 0,217 & 0,148 & 0,174 & 0,168 \\
\hline & & Sim & 0,167 & 0,200 & 0,186 & 0,215 & 0,192 \\
\hline & & Não & 0,126 & 0,185 & 0,135 & 0,157 & 0,151 \\
\hline \multicolumn{8}{|c|}{ Dados Médios } \\
\hline Média & & & 0,146 & 0,192 & 0,161 & 0,186 & 0,171 \\
\hline DP & & & 0,108 & 0,164 & 0,139 & 0,144 & 0,139 \\
\hline \multicolumn{8}{|c|}{ Probabilidades estatísticas - Efeitos principais } \\
\hline $\operatorname{CCS}$ & & & NS & NS & NS & NS & NS \\
\hline MF & & & NS & NS & NS & NS & 0,002 \\
\hline $\mathrm{CCS} * \mathrm{MF}$ & & & NS & NS & NS & NS & NS \\
\hline Dia & & & & & & & 0,001 \\
\hline CCS*Dia & & & & & & & NS \\
\hline MF*Dia & & & & & & & NS \\
\hline CCS*MF*Dia & & & & & & & NS \\
\hline
\end{tabular}

NS: não significativo

De acordo com Santos, Ma e Barbano $^{1}$, o leite pasteurizado com alta CCS foi mais susceptível à lipólise durante o período de armazenamento sob refrigeração. A ocorrência de lipólise no leite pasteurizado durante o armazenamento indica que enzimas lipolíticas são capazes de sobreviver ao processo de pasteurização e manter a sua atividade durante o período de armazenamento. De acordo com estudo de $\mathrm{Ma}$ et al. ${ }^{17}$, o aumento da lipólise no leite pasteurizado durante o armazenamento sob refrigeração indica que as lipases presentes no leite apresentam resistência, pelo menos parcial, à pasteurização, e desta forma mantiveram a sua atividade durante a armazenagem. Os resultados do presente estudo confirmam o aumento da lipólise do leite durante o período de armazenamento sob refrigeração, contudo não foi observado o efeito significativo da CCS sobre a taxa de lipólise do leite.

\section{Análises microbiológicas do leite após o período de armazenamento}

Após o período de armazenamento do leite pasteurizado sob temperatura de $6^{\circ}$ C durante 21 dias, todos os lotes (tratamentos) foram analisados quanto à contagem bacteriana total (CBT) e a contagem de coliformes (CC) para verificar se a adição do conservante foi eficiente. Todos os tratamentos apresentaram CBT inferiores a $10^{5} \mathrm{UFC} / \mathrm{ml}$ e não foram detectados coliformes fecais nas amostras após o armazenamento. Estes resultados confirmam a eficácia do conservante em prevenir a multiplicação microbiana do leite e os seus efeitos sobre a proteólise e lipólise do leite.

\section{Conclusões}

Com base nos resultados obtidos no presente estudo, pode-se concluir que a microfiltração como processo de retirada mecânica das células somáticas do leite resultou em aumento da lipólise do leite durante o período de armazenamento em relação ao leite que não sofreu microfiltração 
e independentemente da contagem de células

somáticas, ocorreu aumento da lipólise do leite pasteurizado durante o período de armazenamento.

\section{Agradecimentos}

Os autores agradecem o auxílio financeiro da Fundação de Amparo à Pesquisa do Estado de São Paulo - FAPESP Proc. 03/08045-1 e a José Franchini Garcia Moreno e Lucinéia Mestieri pelo auxílio técnico.

\section{Effect of somatic cell removal by microfiltration on the lipolysis of milk}

\begin{abstract}
The objective of this study was to evaluate the effects of raw milk somatic cell removal by microfiltration on lipolysis of pasteurized milk during refrigerated storage. A completely randomized design was used, with 3 repetitions and a 2 X 2 X 2 factorial arrangement of treatments as follow: milk fat level (skimmed and whole milk), two different levels of somatic cell counts - low somatic cell count (LSCC) and high somatic cell count (HSCC) - and, use of microfiltration or not. LSCC raw milk - 75,000 cells/ml - and HSCC raw milk - 1,150,000 cells $/ \mathrm{ml}$ - were obtained from selected cows, skimmed and submitted to vacuum microfiltration. Milk from all treatments was pasteurized and kept refrigerated at $6^{\circ} \mathrm{C}$ for 21 days. Repeated measures during storage time were taken from pasteurized milk at days 1, 7, 14 and 21. The application of milk microfiltration was efficient on somatic cell removal, with reduction of 92,5 and 99,5\% for LSCC and HSCC, repectively. Lipolysis of milk was increased during storage period and was higher for milk submitted to microfiltration, however no effect of SCC was observed. Lipolysis in pasteurized milk increased independently of SCC, during its refrigerated storage period.
\end{abstract}

Key words: Milk. Enzymatic activity. Milk fat. Storage.

\section{Referências}

1 SANTOS, M. V.; MA, Y.; BARBANO, D. M. Effect of somatic cell count on proteolysis and lipolysis in pasteurized fluid milk during shelf-life storage. Journal of Dairy Science, v. 86, p. 2491-2503, 2003.

2 SANTOS, M. V. et al. Sensory threshold of off-flavors caused by proteolysis and lipolysis in milk. Journal of Dairy Science, v. 86, p. 1601-1607, 2003.

3 AULDIST, M. J.; HUBBLE, I. B. Effects of mastitis on raw milk and dairy products. Australian Journal of Dairy Technology, v. 53, p. 28-36, 1998.

4 COLLINS, Y. F., MCSWEENEY, P. L. H.; WILKINSON, M. G. Lipolysis and free fatty acid catabolism in cheese: a review of current knowledge. International Dairy Journal, v. 13, n. 11, p. 841-866, 2003.

5 SABOYA, L. V.; MAUBOIS, J. Current developments of microfiltration technology in the dairy industry. Lait, v. 80, n. 6, p. 541-553, 2000.

6 BRANS, G. et al. Membrane fractionation of milk: state of the art and challenges. Journal of Membrane Science, v. 243, n. 1-2, p. 263-272, 2004.

7 SAEMAN, A. I. et al. Effect of mastitis on proteolytic activity in bovine milk. Journal of Dairy Science, v. 71, n. 2, p. 505-12, 1988.

8 VERDI, R. J.; BARBANO, D. M. Preliminary investigation of the properties of somatic cell proteases. Journal of Dairy Science, v. 71, n. 2, p. 534-538, 1988.

9 PEREIRA, D. B. C. et al. Físico-química do leite e derivados - Métodos analíticos. Juiz de Fora: Epamig, 2001. 234 p.

10 SHIPE, W. F. Analysis and control of milk flavor (Include off-flavors). In: CHARALAMBOUS, G.(Ed.). Analytical control of less desirable flavor in food and beverages. New York: Academic Press, 1980. p. 201-239.

11 MA, Y.; BARBANO, D. M.; SANTOS, M. V. Effect of $\mathrm{CO}_{2}$ Addition to Raw Milk on Proteolysis and Lipolysis at $4{ }^{\circ} \mathrm{C}$. Journal of Dairy Science, v. 86, p. 161-1631, 2003. 
12 MARSHAL, R. T. Standard methods for the examination of dairy products. 16. ed. Washington, DC.: American Public Health Assocation, 1992.

13 GIFFEL, M.C.; HORST, H. C. V. D. Comparison between bactofugation and microfiltration regarding efficiency of somatic cell and bacteria removal. Bulletin of the International Dairy Federation, v. 389, p. 4953, 2004.

14 DOWNEY, W. K. Review of the progress of dairy science: Flavour impairment from pre- and postmanufacture lipolysis in milk and dairy products.
Journal of Dairy Research, v. 47, p. 237-252, 1980.

15 CARTIER, P.; CHILLIARD, Y. Spontaneous lipolysis in bovine milk: combined effects of nine characteristics in native milk. Journal of Dairy Science, v. 73, n. 5, p. 1178-1186, 1990.

16 JURCZAK, M. E.; SCIUBISZ, A. Studies on the lipolytic changes in milk from cows with mastitis. Milchwissenschaft, v. 36, n. 4, p. 217-219, 1981.

$17 \mathrm{MA}, \mathrm{Y}$. et al. Effects of somatic cell count on quality and shelf-life of pasteurized fluid milk. Journal of Dairy Science, v. 83, p. 1-11, 2000. 